\title{
The case for a national survey of eating disorders in Australia
}

\author{
L. M. Hart ${ }^{1,2^{*}}$, D. Mitchison ${ }^{3,4}$ and P. J. Hay ${ }^{4}$ (D
}

\begin{abstract}
In this Commentary we outline the case for a national survey of eating disorders in Australia. Given the recent focus of the federal government to provide further funding for mental health research, we call for a national survey to be made a key priority. Such high-quality, nationally representative data are critically important to informing all other domains of eating disorders research in the Australian context, and to informing the research agenda internationally.
\end{abstract}

Australia is in urgent need of a national epidemiological survey for eating disorders (EDs). To date, studies have been limited to specific populations (e.g., female twins [1], adolescents [2]) or States (e.g., South Australia (SA) [3]) and been inadequately powered to detect the full spectrum of EDs $[2,4]$. Whilst anorexia nervosa (AN) and bulimia nervosa (BN) were included in the 1998 Australian Child and Adolescent Survey of Mental Health and Wellbeing [4], binge eating disorder (BED) and eating disorders not otherwise specified (i.e., the more prevalent eating disorders) were excluded [4]. EDs were excluded from the 2013-2014 replication of this adolescent national survey and have never been included in the adult Australian national mental health surveys. Overall this has had the effect of retaining a state of ignorance in terms of the burden of EDs within Australia.

Findings indicate that EDs are common. Hay and colleagues reported a total point-prevalence of any DSM-5 ED of 7.2\% in SA adults in 2015 [3]. Likewise, in the Perth cohort study of 1,600 adolescents, Allen and colleagues reported point prevalence estimates for any DSM-5 ED of $1.2 \%$ and $8.5 \%$ in males and females at age 14 , increasing to $2.9 \%$ and $15.2 \%$, respectively, by age 20 [2]. ED symptoms are also on the rise in Australia. Mitchison and colleagues found the prevalence of at least weekly binge eating increased almost 5 -fold over an

\footnotetext{
* Correspondence: I.hart@latrobe.edu.au

'School of Psychology and Public Health, La Trobe University, Melbourne, Australia

${ }^{2}$ Melbourne School of Population and Global Health, University of

Melbourne, Melbourne, Australia

Full list of author information is available at the end of the article
}

18-year period [5] with parallel increases not only in other behavioural and cognitive ED symptoms [6], but also in the comorbidity of these with obesity [7].

Internationally there are only four published national surveys (United States, Netherlands, New Zealand, Germany) [8-11], all of which were conducted prior to the DSM-5, and all but one limited to AN and BN. Given that DSM- 5 brought in major diagnostic changes that are predicted to impact specific and total ED prevalence [2, 12], national surveys of DSM-5 EDs are needed.

So why has this not been achieved and what are the historical barriers? There is a widespread perception that EDs are uncommon, impacting only a small section of the general population - typically young, White females. This has perpetuated a cycle of misinformation. Historically, EDs were described as disorders of starvation or overeating that affected young females [13] and the earliest disorders to be included in the DSM systems were indeed those more common in younger women (i.e. AN and BN [14]). This characterisation led initial community-based studies to limit their surveys to AN and/or BN and young females and thus widespread underestimation of ED prevalence. Accumulated evidence and the eventual inclusion of BED into the DSM-5 has improved awareness, at least within the ED field, of EDs across genders, the lifespan, and weight status.

The widespread belief that EDs are rare also leads to their low priority in research funding, treatment trials and clinical care. Lack of funding and investigation then reinforces this belief. If it is thought that screening for

(c) The Author(s). 2018 Open Access This article is distributed under the terms of the Creative Commons Attribution 4.0 International License (http://creativecommons.org/licenses/by/4.0/), which permits unrestricted use, distribution, and reproduction in any medium, provided you give appropriate credit to the original author(s) and the source, provide a link to the Creative Commons license, and indicate if changes were made. The Creative Commons Public Domain Dedication waiver (http://creativecommons.org/publicdomain/zero/1.0/) applies to the data made available in this article, unless otherwise stated. 
EDs will offer up few positive cases, and only yield complex diagnoses that are difficult to treat, other disorders will be given priority. Further complicating the case for EDs is that symptoms are ego-syntonic [15] and are often positively rewarded whilst disordered eating behaviours are known to be a strong but maladaptive mechanism for emotional regulation. Thus EDs are often well advanced before treatment is considered [16]. The cumulative effect is that individuals with EDs seek help for co-morbidities (e.g., weight-loss or depression) but not their ED [17]. The lack of visibility of EDs - other than AN - in clinical care also serves to reinforce the notion that EDs are uncommon and low-priority. It also means that other methods of national data collection such as a registry would be a known underestimate because of the low rates of treatment seeking.

With national data, the burden of EDs can be both quantified and located. This information would facilitate targeted and early interventions [7]. At present, EDs are not routinely screened for in primary care settings [18]. This leads to poor management, chronicity, and a costly burden on tertiary health systems [19]. Further, help-seeking for these disorders is very low, at around 10\% [17], even though many symptomatic individuals are in contact with health services [20]. Better understanding the hidden burden of EDs is also likely to lead to better outcomes for concomitant physical (e.g., obesity) and mental health (e.g., depression, anxiety, and substance abuse) outcomes [8].

In 1992 Henderson, wrote "A National Survey was the only way to correct the deficiency [in prevalence data] if national policy was to be guided by sound data" [21]. These sentiments have been echoed internationally. For example, the World Health Organisation global burden of disease study has been criticised for overreliance on poor quality data, even for "mainstream" disorders such as depression and anxiety [22]. Regarding the widely quoted depression estimates, one critical reanalysis of the quality of evidence found few countries had nationally representative data and concluded "the uncritical application of these estimates to international health care policy-making could divert scarce resources from other public healthcare priorities" [23] .

Despite neglect by Australian national mental health surveys $[24,25]$ AN is widely considered the mental illness with the highest mortality rate [26] and as many as $20 \%$ of those deaths attributable to suicide [27]. With an increased focus on suicide prevention among people with EDs [28], a new (2017-2022) national agenda for EDs is resulting in bi-partisan development of EDs policy [29], and new research funding is earmarked for EDs [30,31].

\section{Conclusion}

In conclusion we propose a comprehensive scientific program assessing the full spectrum of EDs and an economic analysis of their burden and the cost effectiveness of primary prevention options. The survey should be longitudinal which would be unique internationally and provide first time national-scale information in the same way that cancer registries currently operate [32, 33]. It would inform the current push to adequately fund EDs research and treatment services, lead to innovations in early intervention, detection and prevention, and provide an important impetus to include EDs in future national mental health surveys in other countries around the world.

\section{Availability of data and supporting materials}

Data sharing not applicable to this article as no datasets were generated or analysed during the current study.

\section{Funding}

LMH is supported by an Australian Rotary Health Post-doctoral research fellowship. Rotary Health has had no involvement in the design of the writing of the manuscript.

\section{Authors' contribution}

LH conceived the argument for a National Survey and drafted the manuscript. DM participated in drafting the manuscript. PH conceived the manuscript and contributed to its content and writing. All authors read and approved the final manuscript.

\section{Ethics approval and consent to participate} Not Applicable.

\section{Consent for publication \\ Not Applicable.}

\section{Competing interests}

Laura Hart and Deborah Mitchison declare no competing interests. Phillipa Hay receives/has received sessional fees and lecture fees from the Australian Medical Council and New South Wales Institute of Psychiatry and royalties/ honoraria from Hogrefe and Huber, McGraw Hill Education, and Blackwell Scientific Publications, Biomed Central and she has received research grants from the NHMRC and ARC. She is Deputy Chair of the National Eating Disorders Collaboration Steering Committee in Australia (2012-) and Member of the ICD-11 Working Group for Eating Disorders (2012-2018) and was Chair Clinical Practice Guidelines Project Working Group (Eating Disorders) of

RANZCP (2012-2015). She is consultant to Shire Pharmaceuticals. All views in this paper are her own.

\section{Publisher's Note}

Springer Nature remains neutral with regard to jurisdictional claims in published maps and institutional affiliations.

\section{Author details \\ ${ }^{1}$ School of Psychology and Public Health, La Trobe University, Melbourne, Australia. ${ }^{2}$ Melbourne School of Population and Global Health, University of Melbourne, Melbourne, Australia. ${ }^{3}$ Department of Psychology, Centre for Emotional Health, Macquarie University, Sydney, Australia. ${ }^{4}$ Translational Health Research Institute, School of Medicine, Western Sydney University, Sydney, Australia.}

Received: 26 July 2018 Accepted: 13 September 2018

Published online: 15 October 2018

\section{References}

1. Wade TD, et al. Prevalence and long-term course of lifetime eating disorders in an adult Australian twin cohort. Aust N Z J Psychiatry. 2006; 40(2):121-8

2. Allen $\mathrm{KL}$, et al. DSM-IV-TR and DSM-5 eating disorders in adolescents: Prevalence, stability, and psychosocial correlates in a population- 
based sample of male and female adolescents. J Abnorm Psychol. 2013;122(3):720-32.

3. Hay P, et al. Burden and health-related quality of life of eating disorders, including Avoidant/Restrictive Food Intake Disorder (ARFID), in the Australian population. J Eat Disord. 2017;5(1):21.

4. Lawrence D, et al. The mental health of children and adolescents: Report on the second Australian Child and Adolescent Survey of Mental Health and Wellbeing. Canberra: Department of Health; 2015.

5. Mitchison D, et al. How abnormal is binge eating? 18-Year time trends in population prevalence and burden. Acta Psychiatr Scand. 2017;136(2):147-55

6. Mitchison D, et al. Time trends in population prevalence of eating disorder behaviors and their relationship to quality of life. PLoS One. 2012;7(11):e48450.

7. da Luz, F., et al., Prevalence of obesity and comorbid eating disorder behaviors in South Australia from 1995 to 2015. Int J Obes, 2017. in press.

8. Hudson JI, et al. The prevalence and correlates of eating disorders in the National Comorbidity Survey Replication. Biol Psychiatry. 2007;61 (3):348-58.

9. Wells JE, et al. Prevalence, interference with life and severity of 12 month DSM-IV disorders in Te Rau Hinengaro: The New Zealand Mental Health Survey. Aust N Z J Psychiatry. 2006:40(10):845-54.

10. Jacobi F, et al. Prevalence, co-morbidity and correlates of mental disorders in the general population: results from the German Health Interview and Examination Survey (GHS). Psychol Med. 2004;34(4):597-611.

11. Bijl RV, Ravelli A, van Zessen G. Prevalence of psychiatric disorder in the general population: results of the Netherlands Mental Health Survey and Incidence Study (NEMESIS). Soc Psychiatry Psychiatr Epidemiol. 1998;33(12):587-95.

12. Hammerle F, et al. Thinking dimensional: prevalence of DSM-5 early adolescent full syndrome, partial and subthreshold eating disorders in a cross-sectional survey in German schools. BMJ Open. 2016;6(5).

13. Bruch H. Evolution of a Psychotherapeutic Approach Eating Disorders: Obesity, Anorexia Nervosa, and the Person Within. New York: Basic Books Inc.; 1973.

14. American Psychiatric Association. Diagnostic and Statistical Manual for Mental Disorders (DSM-III). 3rd ed. Washington DC: American Psychiatric Association; 1980.

15. Fairburn, C.G., Eating Disorders, in eLS. 2001.

16. Natasha H, Paxton SJ. Pathways to help-seeking in bulimia nervosa and binge eating problems: A concept mapping approach. Int J Eat Disord. 2007;40(6):493-504.

17. Hart $L M$, et al. Unmet need for treatment in the eating disorders: $A$ systematic review of eating disorder specific treatment seeking among community cases. Clin Psychol Rev. 2011;31(5):727-35.

18. Fleming J, Szmukler Gl. Attitudes of Medical Professionals towards Patients with Eating Disorders. Aust N Z J Psychiatry. 1992;26(3):436-43.

19. Economics DA. Paying the Price: The economic and social impact of eating disorders. Melbourne: Butterfly Foundation; 2012.

20. Mond $\mathbf{J M}$, et al. Women with bulimic eating disorders: When do they receive treatment for an eating problem? J Consult Clin Psychol. 2009; 77(5):835.

21. Henderson $S$, Andrews $G$, Hall W. Australia's mental health: An overview of the general population survey. Aust N Z J Psychiatry. 2000;34(2):197-205.

22. Polinder $S$, et al. Systematic review of general burden of disease studies using disability-adjusted life years. Popul Health Metrics. 2012;10:21.

23. Brhlikova P, Pollock AM, Manners R. Global Burden of Disease estimates of depression - how reliable is the epidemiological evidence? J R Soc Med. 2011;104(1):25-34.

24. Slade T, et al. 2007 National Survey of Mental Health and Wellbeing: Methods and key findings. Aust N Z J Psychiatry. 2009:43(7):594-605.

25. Andrews G, Henderson S, Hall W. Prevalence, comorbidity, disability and service utilisation: Overview of the Australian National Mental Health Survey. Br J Psychiatry. 2001;178(2):145-53.

26. Keshaviah $\mathrm{A}$, et al. Re-examining premature mortality in anorexia nervosa: A meta-analysis redux. Compr Psychiatry. 2014;55(8):1773-84.

27. Arcelus J, et al. Mortality rates in patients with anorexia nervosa and other eating disorders: A meta-analysis of 36 studies. Arch Gen Psychiatry. 2011; 68(7):724-31.

28. Australian Government Department of Health. National suicide prevention strategy. 201618 July 2018]; Available from: www.health.gov.au/internet/ main/publishing.nsf/content/mental-nsps.

29. The Butterfly Foundation. The National Agenda for Eating Disorders 2017 to 2022. 201718 July 2018]; Available from: www.thebutterflyfoundation.org. au/assets/Uploads/National-Agenda-for-Eating-Disorders-2018.pdf.
30. Australian Government. Medical Research Future Fund - Million Minds Mental Health Research Mission. Canberra: Department of Health, Editor; 2018.

31. Hunt, G. Remarks - University Of Melbourne 2018 Dean's Lecture: The Future Of Mental Health Policy. 201818 July 2018]; Available from: http:// immunise.health.gov.au/internet/ministers/publishing.nsf/Content/healthmediarel-yr2018-hunt180514a.htm.

32. Coleman MP, et al. Cancer survival in Australia, Canada, Denmark, Norway, Sweden, and the UK, 1995-2007 (the International Cancer Benchmarking Partnership): an analysis of population-based cancer registry data. Lancet. 2011;377(9760):127-38.

33. Bilimoria KY, et al. The National Cancer Data Base: A Powerful Initiative to Improve Cancer Care in the United States. Ann Surg Oncol. 2008;15(3):683-90.

\section{Ready to submit your research? Choose BMC and benefit from:}

- fast, convenient online submission

- thorough peer review by experienced researchers in your field

- rapid publication on acceptance

- support for research data, including large and complex data types

- gold Open Access which fosters wider collaboration and increased citations

- maximum visibility for your research: over $100 \mathrm{M}$ website views per year

At BMC, research is always in progress.

Learn more biomedcentral.com/submissions 